\title{
Treatment of sprained ankles by physiotherapists at professional soccer clubs
}

\author{
A. M. LEAMAN ${ }^{1}$ \& D. E. SIMPSON ${ }^{2}$ \\ ${ }^{1}$ Accident and Emergency Department and ${ }^{2}$ Physiotherapy Department ${ }^{3}$, Royal Liverpool \\ Hospital, Liverpool, England
}

\section{SUMMARY}

Fifty-three physiotherapists working at professional soccer clubs responded to a postal questionnaire on the treatment of sprained ankles. Elevation, the application of ice and compression bandaging were commonly recommended for the first 24-48 hours followed by early mobilisation. A variety of other physiotherapy techniques were used and non steroidal anti-inflammatory drugs commonly dispensed. The application of these techniques to routine casualty practice is considered.

\section{INTRODUCTION}

The diagnosis and treatment of sprained ankles form a large part of the work of Casualty Departments. Much time is lost from work by these injuries and many people are temporarily prevented from pursuing their chosen sport.

Physiotherapists at professional soccer clubs are under pressure to return their injured players to match fitness as soon as possible and it was thought that the techniques they use to treat sprained ankles would be of interest to a wider audience. For this reason the methods used by club physiotherapists were sought using a postal questionnaire.

\section{METHOD}

A two-part questionnaire concerning the treatment of sprained ankles was sent to the

Correspondence: $\mathrm{Mr}$ A.M. Leaman, The Casualty Department, Royal Liverpool Hospital, Prescot Street, Liverpool, England. 
physiotherapist at each of the 92 clubs in the Football League. The first part listed $\frac{\pi}{0}$ possible treatments and correspondents were asked which they used and under what $\frac{3}{\infty}$ circumstances. In the second part a hypothetical situation was described in which a first $?$ team player sustained a sprained ankle. With an important FA Cup match in one week's $\underset{\vec{S}}{\stackrel{7}{\rightarrow}}$ time the physiotherapists were asked to say how they would treat the player.

The correspondents were assured of individual confidentiality, and no attempt was made to ascertain whether they held professional physiotherapy qualifications.

\section{RESULTS}

Of the 92 physiotherapists, 53 responded (58\%). The results are summarised in Table $\frac{\mathbb{D}}{3}$ 1. For definitions of the named physiotherapy techniques see Corrigan \& Maitland iv (1983).

Table 1 Summary of results

\begin{tabular}{|c|c|c|}
\hline Technique & & Comment \\
\hline Elevation & $(51)^{*}$ & Usually for first $\mathbf{4 8}$ hours. \\
\hline Application of ice & $(52)$ & In sessions and usually for first $24-48$ hours. \\
\hline Compression strapping & (53) & Usually for first 48 hours. \\
\hline Topical medication & $(24)$ & Movelat (15) or Lasonil (10). \\
\hline Oral medication & $(46)$ & NSAID (46)-usually for 5 days. Chymotripsin (3). \\
\hline Support strapping & $(50)$ & Usually after 48 hours and until injury has settled. \\
\hline Ultrasound & $(47)$ & Usually after 48 hours and until injury has settled. \\
\hline Short-wave therapy & $(30)$ & $\begin{array}{l}\text { Including megapulse, curapulse, electro-magnetic wave } \\
\text { therapy, and microwave. }\end{array}$ \\
\hline Early mobilisation & $(26)$ & Usually as soon as possible. \\
\hline Graded exercises & (53) & $\begin{array}{l}\text { To regain full range of movement and strengthen } \\
\text { affected limb. }\end{array}$ \\
\hline Proprioception exercises & (13) & Including use of wobble board. \\
\hline Other techniques & & $\begin{array}{l}\text { Contrast bathing (17), laser ( } 7 \text { ), frictions (12), } \\
\text { interferential ( } 8 \text {, Maitland's manipulations (3), and } \\
\text { massage (11). }\end{array}$ \\
\hline $\begin{array}{l}\text { Intra- and/or periarticular } \\
\text { medication }\end{array}$ & (15) & $\begin{array}{l}\text { Usually steroid sometimes mixed with local anaesthetic. } \\
\text { Six of the } 15 \text { reserved this for chronic injuries only. }\end{array}$ \\
\hline
\end{tabular}

*The number of clubs using a technique is shown in brackets.

\section{DISCUSSION}

It is reasonable to assume that professional soccer players with sprained ankles are returned to match fitness as soon as possible. Some of the methods used to achieve this are applicable to routine casualty practice although, because of the large numbers of such injuries, techniques which patients themselves can use will be of more practical 
help than methods requiring the skills of a physiotherapist or the use of expensive equipment.

Elevation and the careful application of ice can be recommended to Casualty patients and most departments can provide a safe form of compression bandage. Early mobilisation is used at 26 clubs and its benefits have been demonstrated experimentally (Brooks et al., 1981). The same cannot be said of the routine use of non steroidal antiinflammatory drugs (NSAID). These drugs are not without adverse effects and until they are shown to be more effective than simple analgesia in this setting their use cannot be recommended. Support strapping to encourage early mobilisation is applied at most clubs after the initial swelling has subsided. Casualty Departments will have to decide whether they have the time to offer this additional treatment.

The efficacy of many of the more complex physiotherapy techniques suggested remains unproven and until this has been done their use cannot be regarded as mandatory. However, most would agree that many patients with a sprained ankle would benefit from early referral to a physiotherapist, and where staff levels and funding permit it may be worthwhile having a physiotherapist working full time in the Casualty Department.

Finally, no attempt has been made to assess long-term effects of the treatments described. The premature return to sport of a patient may be welcomed in the short term but may cause disability in the future.

\section{REFERENCES}

Brooks S. C., Potter B. T. \& Rainey J. B. (1981) Treatment for partial tears of lateral ligament of the ankle-a prospective trial. British Medical fournal 282, 606-7.

Corrigan B. \& Maitland G. (1983) Practical Orthopaedic Medicine. Butterworth \& Co., London. 